\title{
Factors Affecting Parents to 'Drop-Out' from Ponseti Method and Children's Clubfoot Relapse
}

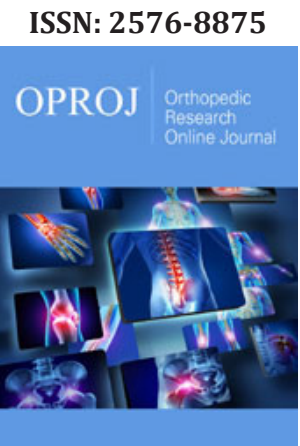

*Corresponding author: Angela Margaret Evans AM, Discipline of Podiatry, School of Science, Health and Engineering, La Trobe University, Melbourne, Australia

Submission: 漈 December 17, 2019

Published: 眥January 07, 2020

Volume 6 - Issue 3

How to cite this article: Angela E, Mamun C, Leila K, Abdur R, Shams U, Obaidul H. Factors Affecting Parents to 'Drop-Out' from Ponseti Method and Children's Clubfoot Relapse. Ortho Res Online J. 6(3) OPROJ.000638.2020.

DOI: 10.31031/OPROJ.2020.06.000638

Copyright@: Angela Margaret Evans AM This article is distributed under the terms of the Creative Commons Attribution 4.0 International License, which permits unrestricted use and redistribution provided that the original author and source are credited.

\author{
Angela Evans ${ }^{1 *}$, Mamun Chowdhury ${ }^{2}$, Leila Karimi ${ }^{3}$, Abdur Rouf ${ }^{4}$, Shams Uddin ${ }^{5}$ \\ and Obaidul Haque ${ }^{5}$ \\ ${ }^{1}$ Discipline of Podiatry, La Trobe University, Australia \\ ${ }^{2}$ Walk for Life Clinical Director, Rajshahi Medical College Hospital, Bangladesh \\ ${ }^{3}$ School of Psychology and Public Health, La Trobe University, Australia \\ ${ }^{4}$ Department of Orthopaedic Surgery, Jessore Medical College Hospital, Bangladesh \\ ${ }^{5}$ Department of Orthopaedic Surgery, Rajshahi Medical College Hospital, Bangladesh
}

\begin{abstract}
Background: Completed treatment of congenital clubfoot deformity using the non-surgical Ponseti method yields very good results. However, many children do not complete the treatment course, potentiating relapse of the deformity, forever compromising independent gait and quality of life. If the factors precipitating 'drop out' from treatment can be averted, more children will complete the Ponseti method of treatment which has low rate of complication and is both economical and highly effective. Children depend on parents to bring them to the clinics, hence we aimed to identify factors obstructing parents and ultimately the children's outcomes. Once identified, barriers to completing treatment may be removed.
\end{abstract}

Aim: To identify the factors obstructing completion of clubfoot treatment.

Method: Two of the 32 Walk for Life (WFL) clubfoot clinics in Bangladesh were utilised for participants, who were parents and children $(n=72)$ who had dropped out from completing the clubfoot treatment course four to six years earlier. Bootstrapping was used to improve statistical power (based on 1000 random sample). Validated outcome measures included a specific context drop out questionnaire, the Oxford Ankle Foot questionnaire, the Bangla clubfoot assessment, and the Foot Posture Index. Parent's insights, experiences and recommendations were canvassed both qualitatively and quantitatively.

Result: Relapse occurred in 15/72 drop out cases, predicted by problems with the initial casting process. The main reasons for drop out were difficulty with the foot abduction brace (42\%), family issues (31\%), and other problems with the child's clubfoot treatment (15\%). Despite problems and incompletion, the parents were generally satisfied (93\%), although many felt sad or ashamed for not completing the treatment course and realizing clubfoot deformity recurrence (96\%). Parents who had dropped out, were noted by WFL staff to be regretful, and especially so if their now older child's clubfoot had relapsed to obviously compromise independent gait and mobility. A lack of discernment of postural clubfeet from 'true' clubfeet was identified in some clinicians, indicating variable practice methods despite uniform training, and probably lowering the overall relapse rate with inclusion of 'postural' cases.

Conclusion: Relapse was predicted by problems with casting and predicted worse foot posture and reduced physical functioning. Walk for Life adopted appointment reminders, parent support groups, cost sharing, and staff updates.

Keywords: Ponseti; Relapse; Clubfoot; Barriers; Parents; Children

\section{Introduction}

Congenital talipes equino varus deformity (CTEV, or clubfoot) is a significant congenital paediatric orthopaedic deformity. Without treatment, affected children are assuredly disabled, due to decreased mobility, pain, calluses, skin breakdown, and inability to wear standard footwear. Disability and poverty are demonstrably linked [1]. In low- and middleincome countries (LMICs) where $90 \%$ of affected children reside, less than $15 \%$ receive treatment [2]. The last 20 years have seen the management of CTEV transformed by the nonsurgical Ponseti method, which is recognised as the global 'gold standard' treatment for CTEV and is largely supported by evidence [3]. Globally, the incidence of CTEV is 1.24: 1000 live 
births [4]. In Bangladesh, this approximates 3,500 new cases of CTEV annually. Walk for Life (WFL) is the National Clubfoot Project of Bangladesh, a not-for-profit aid project, which has diligently evaluated and disseminated the findings by publication [5-8]. Since 2009, WFL have treated over 25,000 Bangladeshi children with CTEV, making it one of the largest clubfoot projects in the world. Whilst the overall results of WFL are very good, in common with all clubfoot projects, especially in LMICs, some failure of treatment is due to 'drop-out'. It is well-reported that drop out means children usually retain disability $[3,9,10]$. Previously, WFL found that only 99/147 cases were available for follow up after four years [5]. The drop-out estimate at WFL clinics is $20 \%$, based on enrolment versus completion numbers, with most incompletions arising during the bracing period, with non-yielding phone/SMS follow up greater than 6 months.

Recently, global findings of clubfoot treatment provision revealed that only $53 \%$ of children continued brace use after two years, yet this is recommended to age four to five years to reduce the risk of relapsing deformity (estimated at 30-80\% two years after initial treatment) [2]. If the factors precipitating drop out can be averted, more children will complete the Ponseti method of treatment which has low rate of complication and is both economical and highly effective [11]. This study aimed to determine the factors contributing to drop out from clubfoot treatment in Bangladesh. We also aimed to determine the effect of drop-out on children's gait and quality of life, and to explore the perspectives of parents.

\section{Materials and Methods}

\section{Patients}

Parents and children who had dropped out between 2012 and 2014, were invited to participate in the study. The children reviewed were school age, hence expected to have independent gait. Informed consent was obtained at enrolment. Demography included children's age, sex, height, weight, and CTEV treatment.

\section{Procedure}

Two of WFL's 32 clinics were purposively selected and contrasted. Jessore, the first clinic, since 2009 to 28 February 2018, had enrolled 1055 children, whilst Rajshahi, the largest clinic, since 2010 to 28 February 2018, had enrolled 1143 children. Rajshahi was referenced for dropout rate, i.e. 406 children enrolled between 2014 and 2016 [2014-154; 2015-138; 2016-114]. A 20\% drop-out estimate: 2014-30; 2015-27; 2016-22 ( $\mathrm{n}=79$ total). Convenient samples intended 40 parents and children for review over two days at both clinics, aspiring to a sample size, $\mathrm{n}=80$.

Four specific outcome measures were used:

a) Bangla 'drop out' Questionnaire for Parents (BDOQP), $[5,12]$ was developed from the parallel themes of investigations exploring reasons for drop out, viz: financial, transport, social and attitudinal, practical factors, in Uganda, Malawi, Latin America, and Madagascar [12-15]. Additionally, parent recommendations were sought. b) Oxford Ankle Foot Questionnaire-Children (OXAFQ-C), $[16,17]$ The parent version of this validated instrument assesses disability associated with foot and ankle problems in children aged five to 16 years. Scores cover three domains: physical, school and play, emotional.

c) Bangla Clubfoot Assessment Tool (BCAT), [6] is a reliable instrument addressing: parent satisfaction, gait assessment, clinical foot examination.

d) The Foot Posture Index (FPI-6), [18] has normative paediatric data [19] and compared foot status with healthy children.

\section{Statistical analysis}

Data were collected in February 2018, and entered in spreadsheets (Excel, Microsoft Corp) for analyses. Further analysis used SPSS version 24 (IBM Corp, 2016). Descriptive statistics were applied to demographic data, assessments, and parent questionnaires. Relationships between variables were analysed using Spearman's rho (FPI and relapse signs). A logistic model was fitted to the data, to identify relationship between the likelihood of clubfoot relapse being predicted by specific independent variables, in children who had dropped out of treatment. Preliminary correlation analysis carried out at the first step, then selected the more significant variables to be included in the model.

The statistical significance of individual regression coefficients was tested using the Wald chi-square statistic. For model evaluation, The Omnibus Tests of Model Coefficients is used to evaluate the proposed model. The -2LL (-2 Log Likelihood) and Nagelkerke-R2 values were also reported for the full model. The Nagelkerke-R2 values demonstrate the variation in the outcome is explained by the model. The Hosmer \& Lemeshow test used to test for the model goodness of fit. Due to the small sample size, Bootstrapping procedure of 1000 random sample was used to increase the power of sample size and to calculate the confidence intervals to estimate a population parameter.

\section{Result}

\section{Patient characteristics}

A total of 72 children and parents participated in the study from the two clinics, Rajshahi $(n=42)$ and Jessore $(n=30)$. The sample included 40 males, and 32 females. The mean age was 4.4(1.1) years, ranging from 2.0-8.0 years. Basic anthropometry included height (mean 98.3(8.7) cm, range 83.0-117.0cm), weight (mean 14.3(2.6)kgs, range 9.0-21.0kgs), from which BMI was calculated (mean 14.7(1.6), range 10.2-19.0). Bilateral clubfeet were present in 36 children, with right only in 24 children and left foot only in 12 children.

\section{Parent's experiences}

The parent questionnaire data are presented as demographic (Table 1) and drop-out (Table 2), including logistics (financial, transport), treatment experiences and parent recommendations (see Supplementary data 1,2,4). The BDOQP compared parent's 
recall with the clinical records (Table 1). There was discrepancy between parent recall and clinician records, with parent recall underestimating the age of children at first cast by 40 days (almost six weeks). Two parents did not recall their child's tenotomy procedure (and associated three-week leg casts). Parents overestimated the number of corrective casts by one cast, and brace use by an additional three months. In all cases, drop out occurred during the brace period. All used the brace initially, with drop out beginning after one month. The mean age of children at the time of drop out was 2.6 years, and the main reasons cited were: difficulty with brace $(42 \%)$, family issues $(31 \%)$, problems with treatment (15\%) (Table 2).

Table 1: Clubfoot treatment summary as recalled by parents, versus the clinical records ( $\mathrm{n}=72$ ) using the Bangla 'drop out' Questionnaire for Parents (BDOQP).

\begin{tabular}{|c|c|c|c|c|c|c|c|c|}
\hline & $\begin{array}{l}\text { Recalled } \\
\text { Age Cast } 1 \\
\text { (Days) }\end{array}$ & $\begin{array}{l}\text { Recorded Age } \\
\text { Cast } 1 \text { (Days) }\end{array}$ & $\begin{array}{l}\text { Recalled } \\
\text { No. Casts }\end{array}$ & $\begin{array}{l}\text { Recorded No. } \\
\text { Casts }\end{array}$ & $\begin{array}{c}\text { Recalled } \\
\text { PAT }\end{array}$ & $\begin{array}{l}\text { Recorded } \\
\text { PAT }\end{array}$ & $\begin{array}{l}\text { Recalled } \\
\text { FAB Use }\end{array}$ & $\begin{array}{c}\text { Recorded FAB } \\
\text { Use }\end{array}$ \\
\hline Mean (SD) & $88(141)$ & $128(183)$ & $5.8(3.5)$ & $5.0(2.9)$ & $0.71(0.4)$ & $0.74(0.4)$ & 1 year (3mths) & $\begin{array}{c}\text { 6-12 months } \\
\text { (3mths) }\end{array}$ \\
\hline Median & 30 & 45 & 4 & 5 & 1 & 1 & 2 years & 1 year \\
\hline Range & 718 & 719 & 13 & 13 & 2 & 1 & $0-3$ years & $0-4$ years \\
\hline Min & 2 & 1 & 2 & 1 & 0 & 0 & 0 -3mths & $0-3$ mths \\
\hline Max & 720 & 720 & 15 & 14 & 2 & 1 & 4 years & 4 years \\
\hline $\begin{array}{l}\text { Average } \\
\text { recall vs } \\
\text { report }\end{array}$ & $\begin{array}{c}88 \\
(2-720)\end{array}$ & $\begin{array}{c}128 \\
(1-720)\end{array}$ & $\begin{array}{c}6 \\
(2-13)\end{array}$ & $\begin{array}{c}5 \\
(1-14)\end{array}$ & $\begin{array}{l}49 \text { yes } \\
22 \text { no }\end{array}$ & $\begin{array}{l}51 \text { yes } \\
18 \text { no }\end{array}$ & $\begin{array}{c}1 \text { year } \\
\text { (0-4 years) }\end{array}$ & $\begin{array}{l}\text { 6-12mths } \\
\text { (0-4 years) }\end{array}$ \\
\hline $\begin{array}{l}\text { Recall dif- } \\
\text { ference }\end{array}$ & -40 days & & +1 cast & & -2 PAT & & $+3 \mathrm{mths}$ & \\
\hline
\end{tabular}

Table 2: Responses to the Bangla 'drop out' Questionnaire for Parents (BDOQP) showing financial and transport parameters, social attitudes, experiences and recommendations.

\begin{tabular}{|c|c|c|c|c|c|}
\hline \multicolumn{6}{|c|}{ Age of Child at Drop Out, $n=71$} \\
\hline$<1$ year & 1 year & 2 years & 3 years & 4 years & 5 years \\
\hline 4 & 13 & 21 & 21 & 11 & 1 \\
\hline \multicolumn{6}{|c|}{ Main Reason for Drop Out, $\mathbf{n = 7 0}$} \\
\hline Transport & Treatment & Financial & Brace use & Appointment times & Family problems \\
\hline 2 & 11 & 5 & 30 & 0 & 22 \\
\hline \multicolumn{6}{|c|}{ Housing data, a Proxy Indicator for Affluence, $n=72$} \\
\hline House type & & Location & & & \\
\hline Tin - 32 & Mud - 21 & Town - 9 & & & \\
\hline Wood - 5 & Brick - 14 & Rural - 63 & & & \\
\hline \multicolumn{6}{|c|}{ Financial Influences, $n=72$} \\
\hline & & Yes & No & & \\
\hline Could par & or treatment? & 12 & 60 & & \\
\hline \multicolumn{2}{|c|}{ Did treatment visits cause financial issues? } & 37 & 35 & & \\
\hline \multicolumn{6}{|c|}{ Transport Factors, and Mode of Travel to Clinic, $n=71$} \\
\hline Bus & Taxi & Walk & Train & Auto rickshaw & Other \\
\hline 60 & 2 & 0 & 4 & 5 & 0 \\
\hline \multicolumn{6}{|c|}{ Difficulties Reported when Travelling to Clinics, $n=72$} \\
\hline Cost & Time & Carrying baby & Train & No difficulty & \\
\hline 10 & 14 & 6 & 4 & 38 & \\
\hline
\end{tabular}




\begin{tabular}{|c|c|c|c|c|c|}
\hline \multicolumn{6}{|c|}{ Distances Travelled to Clinics, $n=68$} \\
\hline $10 \mathrm{~km}$ & $30 \mathrm{~km}$ & $50 \mathrm{~km}$ & $80 \mathrm{~km}$ & $100 \mathrm{~km}$ & $150 \mathrm{~km}$ \\
\hline 6 & 3 & 3 & 24 & 16 & 16 \\
\hline \multicolumn{6}{|c|}{ Social Attitudes and Emotions Experienced by Parents, $n=71$} \\
\hline Felt sad & Told family & Felt blamed & \multicolumn{2}{|c|}{ Negative reactions from others } & \\
\hline Yes - 69 & No - 18 & Yes - 17 & \multicolumn{2}{|c|}{ Yes - 24} & \\
\hline \multicolumn{6}{|c|}{ Treatment Stage Found Difficult, $n=67$} \\
\hline Casts & Tenotomy & Tenotomy cast & Brace & Other & None \\
\hline 10 & 1 & 1 & 5 & 0 & 50 \\
\hline \multicolumn{6}{|c|}{ Treatment Stage when Child Cried, $n=72$} \\
\hline Casts & Tenotomy & Tenotomy cast & Brace & Other & None \\
\hline 58 & 38 & 1 & 38 & 2 & 0 \\
\hline \multicolumn{6}{|c|}{ Treatment Stage Associated with Reported Problems, n=72 } \\
\hline Casts & Tenotomy & Tenotomy cast & Brace & Other & None \\
\hline 6 & 0 & 2 & 2 & 0 & 57 \\
\hline \multicolumn{6}{|c|}{ Parents' Recommendations for Clubfoot Treatment, n=72 } \\
\hline & & Yes & No & & \\
\hline \multicolumn{2}{|c|}{ Service quality needs to improve } & & & & \\
\hline & & 5 & 67 & & \\
\hline & my & 2 & 67 & & \\
\hline & & 4 & 68 & & \\
\hline & o be free & 70 & 2 & & \\
\hline & ubsidy & 61 & 11 & & \\
\hline Staff attitu & eed to improve & 8 & 64 & & \\
\hline & times & 4 & 68 & & \\
\hline & tments & 69 & 3 & & \\
\hline & oup & 71 & 1 & & \\
\hline
\end{tabular}

Table 2 presents financial factors, with housing data as a proxy measure of affluence. Generally lower affluence is found in rural environs; and in mud>wood>tin>brick housing structures. Only $17 \%$ stated that they could have afforded to pay for treatment (provided free by WFL). The most usual transport to clinics were local buses (85\%), and almost half reported transport difficulties (47\%), with $77 \%$ travelling at least $80 \mathrm{~km}$. Overnight accommodation was required by $3 / 72$ (4\%). Parents reported feeling sad about their child's clubfoot (97\%), 24\% hid the clubfoot from family, 25\% (mothers) felt blamed for the clubfoot, and $34 \%$ reported negative attitudes from others about their child's clubfoot. Most parents found treatment manageable (75\%), with most difficulty during casting (weekly clinic visits, carrying a child with leg casts, 15\%). Most parents reported their child cried when cast (81\%), tenotomy (53\%) and brace use (53\%). Most parents (79\%) reported no problems during the treatment course, but most reported problems were during initial casting (8\%). Parent recommendations were: $97 \%$ free treatment, $85 \%$ transport subsidy, $11 \%$ better staff attitudes, 95\% more appointment times and reminders, 99\% parent support group.

\section{Children's examinations}

The OXAFQ-C, [20] school and play domain revealed lower function with $40(55 \%)$ children scores $<50 \%$. The median BCAT score was 7/11 (64\%) with higher scores indicating better outcomes. Parent satisfaction was $<50 \%$ in $16 / 72$ (22\%), gait scored $<50 \%$ in $5 / 72$ children (7\%), and clinical foot assessment scored $<50 \%$ in 24 children (33\%). FPI was compared with normative childhood score of $4+/-3(19)$ and 28 (46\%) had FPI scores $<0$, indicative of relapse (see Supplementary data 1, 2, 3).

\section{Foot and gait assessment}

Relapsed clubfoot in $15 / 72$ (21\%) of the sample, reviewed four to six years after beginning treatment, with $7 / 72(9.7 \%)$ fully relapsed (Figure 1). Two full relapses occurred in children with wider diagnoses. Partial relapse was seen in 8/72 (11.1\%) children, although these feet were plantigrade, and children walked independently [21] (Figure 2). There was significant relationship between FPI and clubfoot relapse signs, viz. heel inversion-FPI (rho 0.750), ankle dorsiflexion-FPI (rho 0.701), heel inversion-ankle dorsiflexion (rho 0.676) $(\mathrm{p}<0.01)$. The fully relapsed feet displayed 
negative FPI indicative of supinated foot posture and ranged from -6 to -12 (in partial relapses the FPI ranged from -1 to -5 ). Three children were able to walk independently, with slow gait and limping, of the seven fully relapsed. However, they could not squat, even if able to run and manage steps. The ability to squat has been identified as a sensitive test for relapse [5,22].

\section{Clubfoot relapse prediction}

Predictors of clubfoot relapse were explored using regression analysis (Table 3). The dependent variable which indicated deformity relapse was coded as 'Yes' is equal to $1(\mathrm{n}=15)$ and 0 was coded for no relapse $(n=53)$. Since the dependent variable was discrete, logistic regression estimated the factors that are associated with relapse. The model evaluation of -2LL value for this model (21.94) and Omnibus test of model coefficients $(\mathrm{p}<0.05)$ supported the model. The Hosmer \& Lemeshow test of the goodness of fit suggests the model is a good fit to the data ( $p>0.05)$.

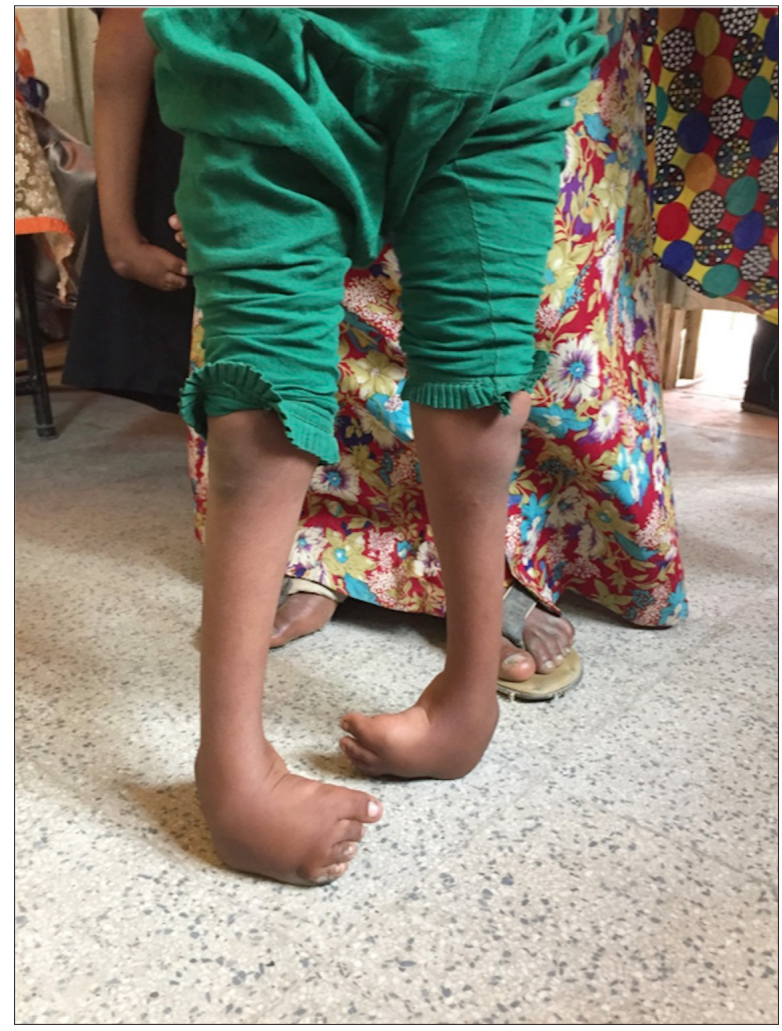

Figure 1: A fully relapsed of clubfoot deformity following incomplete treatment in a child age five years.

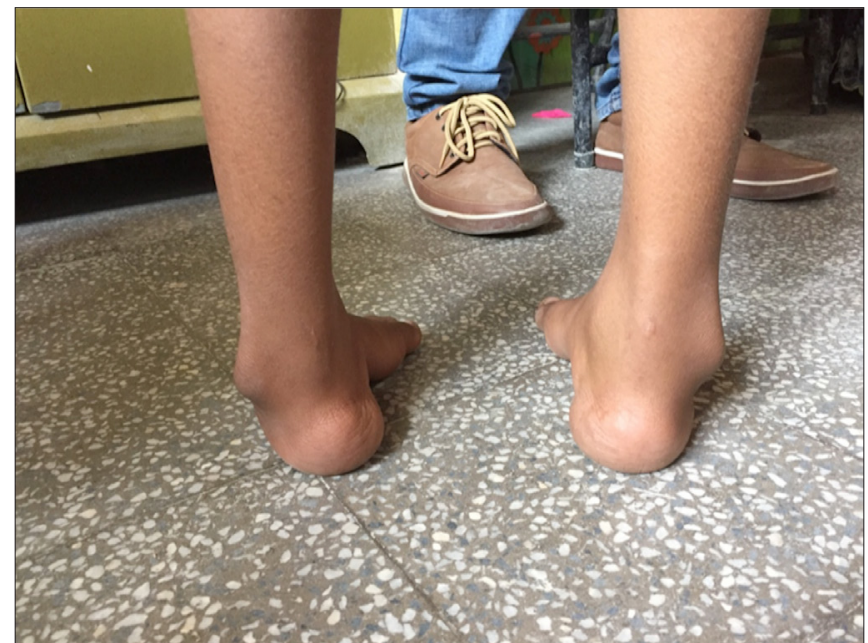

Figure 2: A partial relapse of clubfoot deformity where the feet were plantigrade, supinated, and the child walked independently. 
The Nagelkerke's R squared indicates the power of explanation of the model ranging from 0 to 1 . Nagelkerke's R2 for model is 0.78 and explains $49 \%$ to $76 \%$ of the variance, which contributed to the dependent variable (deformity relapse) by independent variables of model (i.e. problems with casting, foot posture/FPI, physical functioning/OXAFQ-C) (Table 3). Three variables (problems with casting, foot posture/supinated FPI, physical functioning/ OXAFQ-C) were significant predictors of relapse among children who had dropped out from treatment $(p<0.05)$. Based on the results, the log of the odds of a child's foot relapse, with drop out, was negatively related to foot posture/FPI $(\mathrm{p}<0.05)$, positively related to problems with casting $(\mathrm{p}<0.05)$ and negatively related to physical functioning/OXAFQ-C $(\mathrm{p}<0.05)$. In other words, the odds of foot relapse increased, when there were reported problems with casting, and relapse predicted it was less likely for the child to have good foot posture, and also less likely to have good physical functioning. Note that the results of bootstrapping of 1000 random sample support the results except for the physical functioning $(p=0.08)$.

Table 3: Logistic regression results with relapse as the dependent variable.

\begin{tabular}{|c|c|c|c|c|c|c|c|}
\hline & \multirow{2}{*}{\multicolumn{5}{|c|}{$\begin{array}{l}\text { 95\% Interval } \\
\text { Confidence }\end{array}$}} & \multicolumn{2}{|c|}{ Bootstrap $^{a}$} \\
\hline & & & & & & \multirow[b]{2}{*}{ Lower } & \multirow[b]{2}{*}{ Upper } \\
\hline & & B & Wald & Sig. & Odds Ratio & & \\
\hline \multirow{7}{*}{ Step $1^{a}$} & LTS & -0.673 & 9.023 & 0.003 & 0.51 & $-65.245^{b}$ & $-.413^{\mathrm{b}}$ \\
\hline & OXPHYSTOT & -0.239 & 4.364 & 0.037 & 0.788 & $-20.128^{b}$ & $.783^{\mathrm{b}}$ \\
\hline & TxProblem14 & & 7.527 & 0.057 & & & \\
\hline & TxProblem14(1) & 4.599 & 7.527 & 0.006 & 99.362 & $-.028^{\mathrm{b}}$ & $456.303^{\mathrm{b}}$ \\
\hline & TxProblem14(2) & -0.074 & 0 & 0.991 & 0.929 & $-92.275^{b}$ & $198.200^{\mathrm{b}}$ \\
\hline & TxProblem14(3) & -18.185 & 0 & 0.999 & 0 & $-19.504^{b}$ & $169.871^{b}$ \\
\hline & Constant & 1.681 & 0.646 & 0.422 & 5.37 & $-134.757^{b}$ & $273.632^{\mathrm{b}}$ \\
\hline \multicolumn{2}{|c|}{ Model Omnibus Test } & 46.74 & 5 & 0.001 & & & \\
\hline \multicolumn{2}{|c|}{ Hosmer and Lemeshow Test } & 0.72 & 8 & 0.99 & & & \\
\hline \multicolumn{2}{|c|}{ Nagelkerke $\mathrm{R}^{2}$} & 0.78 & & & & & \\
\hline
\end{tabular}

${ }^{a}$ Unless otherwise noted, bootstrap results are based on 1000 bootstrap samples.

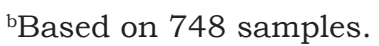

\section{Clinic disparity}

Data was collected from two clinics. Whilst the training of all clinical staff at WFL is uniform, data analysis revealed a disparity between the two clinics regarding recognition and subsequent management of children with postural versus typical clubfoot deformity. The number of casts differed substantially between clinics, as did the age of babies at initial presentation (Table 4; anonymized as Clinic 1 and Clinic 2). It was not known prior to the commencement of the study, that this disparity existed, and hence the inclusion of children with postural clubfeet was subsequently identified as a study limitation (and an issue for staff training and appraisal).

Table 4: Comparative clinic data for children who had three or less corrective plaster casts, indicating a high likelihood of postural clubfeet being treated at Clinic 2, and comparison of general clinic trends.

\begin{tabular}{|c|c|c|}
\hline Child Had $\mathbf{3}$ or Less Casts & Clinic 1 & $26(36 \%)$ \\
\hline Number of children (n) & $3(4 \%)$ & 21 \\
\hline a) age $<45$ days & - & - \\
b) age $<60$ days & 2 & 19 \\
\hline Tenotomy performed & 0 & 8 \\
\hline Brace cessation & - & 7 \\
\hline a) 6 months & - & \\
\hline b) 2 years & & 2.6 \\
\hline General Clinic Frequencies (n=72) & 6.8 & \\
\hline
\end{tabular}




\begin{tabular}{|c|c|c|}
\hline Casting without child crying & 11 & 2 \\
\hline Problems with casting & 8 & 2 \\
\hline Relapsed cases & 4 & 3 \\
a) full & 6 & 2 \\
b) partial & 6 & \\
\hline
\end{tabular}

\section{Discussion}

Drop out from clubfoot treatment is well-reported, with estimates ranging from 14 to $41 \%$ [12,23-25], with estimates in Bangladesh approximating 20\%. This study has deliberately targeted this cohort in effort to better understand the reasons for drop out, as this thwarts otherwise good outcomes. It is well acknowledged that the serial nature of the Ponseti method, presents challenges for parents and families [1,3]. Some obstacles encountered during clubfoot treatment are known, e.g. travel distances, prolonged treatment course, parent's understanding, family concerns [23]. Harmer et al. [9] reported six barriers restricting access to clubfeet care in Uganda: lack of program resources, distance to treatment, poverty, poor paternal support, caregiver's other responsibilities, and treatment challenges. Factors which encouraged access to treatment, included: outreach services, counseling caregivers, family harmony, and excellent care. Similarly, in Tanzania, only $10 \%$ of children referred to a hospital for treatment, were actually treated, with reasons including: poor communication, travel expense, parental reluctance to leave home in a sustenance farming-based economy. Comparable barriers to care also exist in Brazil and Malawi [9]. This issue has not been explored in Bangladesh where an estimated 3,500 children with clubfoot are born annually, and which has one of the world's largest clubfoot projects, with over 25,000 children enrolled since 2009.

This study found that the main reasons for 'drop out' were finding aspects of treatment difficult, especially casting and bracing. Difficulty during bracing has been reported elsewhere [26,27]. However, many dropped out due to wider family circumstances, which prevented returning to clinics. Drop out always occurred during bracing, by which stage children were older than two years, and walking. The many competing demands for parents were further complicated by a lack of understanding of the importance of the night-time brace, a frequent retrospective lament. Coupled with travel distances and cost, time away from home and work, sadness and social stigma about their child's clubfoot deformity, it is understandable that some parents drop out.

The recommendations from parents to prevent drop out were practical: appointment reminders, parent support groups, financial support for travel and treatment, improved attitude and manner of clinicians. Having identified these issues, WFL has instigated SMS appointment reminders, parent information groups (group appointments for brace follow up enabling mothers/parents to support and learn from each other and clinicians), a cost recovery framework with cooperation with Government of Bangladesh (scaled payment according to affluence, free treatment continuing for impoverished families), staff renewal and standards review, ongoing evaluations to improve outcomes, including monitoring via mobile phone application (app: Clubfoot Administration SystemCAST).

Perhaps the most remarkable finding was the few full relapses, given that all treatment was incomplete. Does this indicate a critical 'dosage' of treatment, beyond which relapse of deformity is less likely? This is an area for further investigation, but another factor was identified by review of cast practices. The disparity between clinics indicates a lack of discernment of postural clubfeet, and typical clubfeet, and is a limitation of this study (potentially lowering the relapse rate). Postural clubfeet are positional, not structural, most reduce with time, and the evidence for any treatment is disputed [28]. It was apparent that postural clubfeet were not discerned from 'true' clubfeet by some clinicians. The high proportion of children 'corrected' with three or less casts is unusual, and should alert clinicians, given the average number of Ponseti casts is five to six $[29,30]$. Also notable was that most of the few-cast cases were less than six weeks of age at the time of first cast. Reviewing large-scale projects may identify systemic issues, but enables amelioration, and improved outcomes, as WFL previously found with complex clubfeet $[8,31]$.

Unique exploration of children with relapsed deformity, identified a predictive factor for relapse being problems with casting. Whilst the numbers of reported cast problems were low, this has not been previously identified in Bangladesh. Indeed, casting is regarded as straightforward. Perhaps casting per se is influenced by the experience of young, worried parents in crowded clinics, with busy clinicians. Longer term, clinicians become used to routine practice, and may overlook the novelty for parents and children. Parents reported that most children cried during casting, which must be distressing. Whilst babies do cry, this can be reduced when clinicians build basic rapport, and adopt gentle technique.

Treatment with repeated Ponseti cast/brace, and surgical procedures (tendon transfers/lengthening and capsular releases) is possible for relapsed cases, but clearly undesirable in terms of resources, experience, and outcomes [32,33]. Overall, parents were reasonably happy with the results, given that most children were walking, even though some children's feet showed signs of relapse. Parents repeatedly expressed their disappointment during data collection, once they realized the importance of brace use, which was an aspect of the treatment that had not been well appreciated. This study identified that clubfoot relapse can be predicted from problems with initial casting. This is new knowledge, as the brace is generally regarded as more difficult and associated with drop out. Initial casting achieves correction of deformity, and simultaneously clinicians need to educate and support parents and their children. 
This is demanding for busy clinicians in high case-load, low resource settings. This study confirms many of the barriers identified in LMIC settings, viz. travel, poverty, family demands, treatment difficulties, understanding of brace use. Every child/parent participating in this study had dropped out from completing the four-year clubfoot program, and whilst all dropped out during bracing, some instances were likely catalyzed by earlier cast problems. Parents reported feeling sad and stigmatized from their child's clubfoot deformity, making recommendations to improve compliance, which have been implemented utilizing information technology-SMS, Facebook, phone app for clinic data. A refresher (postural versus typical clubfeet) is planned for staff education and training. WFL maintains a good relationship with the Bangladesh Ministry of Health, with cooperative practices to instigate fair cost and resource sharing. As Bangladesh moves from low to middle income country status, the issues of cost sharing, IT communications, clinician KPI's, and ongoing evaluation of these large-scale outcomes, will become even more relevant.

\section{Acknowledgement}

The authors gratefully acknowledge the following groups and individuals: all participating parents and children; Arif and Porat - translators; Sem Mabuwa - Action on Poverty; Team members at Walk for Life - Bangladesh; Major General Dr Md Fashiur Rahman Armed Forces Medical College, Dhaka Cantonment, Bangladesh; All Senior Medical, Allied Health and Administrative Staff - Jessore and Rajshahi Medical Colleges; Ministry of Health and Family Welfare, Bangladesh Government; The People's Republic of Bangladesh.

\section{References}

1. Harmer L, Rhatigan J (2013) Clubfoot care in low-income and middleincome countries: From clinical innovation to a public health program. World J Surg 38(4): 839-848.

2. Owen RM, Capper B, Lavy C (2018) Clubfoot treatment in 2015: A global perspective. BMJ Glob Health 3(4): e000852.

3. Van Bosse HJ (2011) Ponseti treatment for clubfeet: An international perspective. Curr Opin Pediatr 23(1): 41-45.

4. Smythe T, Kuper H, Macleod D, Foster A, Lavy C (2016) Birth prevalence of congenital talipes equinovarus in low- and middle-income countries: A systematic review and meta-analysis. Trop Med Int Health 22(3): 269285.

5. Evans AM, Chowdhury MMH, Kabir MH, Rahman MF (2016) Walk for life - the National clubfoot project of Bangladesh: The four-year outcomes of 150 congenital clubfoot cases following Ponseti method. Journal of Foot and Ankle Research 9(1): 42.

6. Evans AM, Perveen R, Ford-Powell VA, Barker S (2014) The Bangla clubfoot tool: A repeatability study. Journal of Foot and Ankle Research $7(1): 27$.

7. Perveen R, Evans AM, Ford-Powell V, Dietz FR, Barker S, et al. (2014) The Bangladesh clubfoot project: Audit of 2-year outcomes of Ponseti treatment in 400 children. Journal of Pediatric Orthopedics 34(7): 720725.

8. Ford-Powell VA, Barker S, Khan MSI, Evans AM, Deitz FR (2013) The Bangladesh clubfoot project: The first 5000 feet. Journal of Pediatric Orthopedics 33(4): e40-e44.

9. Harmer L, Rhatigan J (2014) Clubfoot care in low-income and middleincome countries: From clinical innovation to a public health program. World J Surg 38(4): 839-848.
10. Liu Y, Zhao D, Zhao L, Li H, Yang X (2015) Congenital clubfoot: Early recognition and conservative management for preventing late disabilities. Indian J Pediatr 83(11): 1266-1274.

11. Shabtai L, Specht SC, Herzenberg JE (2014) Worldwide spread of the ponseti method for clubfoot. World J Orthop 5(5): 585-590.

12. Ramahenina H, Connor RJ, Chamberlain MA (2016) Problems encountered by parents of infants with clubfoot treated by the ponseti method in Madagascar: A study to inform better practice. J Rehabil Med 48(5): 481-491.

13. Boardman A, Jayawardena A, Oprescu F, Cook T, Morcuende JA (2011) The ponseti method in Latin America: Initial impact and barriers to its diffusion and implementation. Iowa Orthop J University of Iowa 31: 3035 .

14. McElroy T, Konde-Lule J, Neema S, Gitta S, Uganda Sustainable Clubfoot Care (2007) Understanding the barriers to clubfoot treatment adherence in Uganda: A rapid ethnographic study. Disabil Rehabil Taylor \& Francis 29(11-12): 845-855.

15. Lavy CBD, Mannion SJ, Mkandawire NC, Tindall A, Steinlechner C, et al. (2007) Club foot treatment in Malawi - a public health approach. Disabil Rehabil 29(11-12): 857-862.

16. Morris C, Doll H, Davies N, Wainwright A, Theologis T, et al. (2009) The oxford ankle foot questionnaire for children: Responsiveness and longitudinal validity. Qual Life Res Springer Netherlands 18(10):13671376.

17. Morris C, Doll H, Wainwright A, Davies N, Theologis T, et al. (2010) The oxford ankle foot questionnaire for children: Review of development and potential applications. Informa Healthcare London 34(3): 238-244.

18. Redmond AC, Crosbie J, Ouvrier RA (2006) Development and validation of a novel rating system for scoring standing foot posture: The foot posture index. Clinical biomechanics (Bristol, Avon) 21(1): 89-98.

19. Gijon-Nogueron G, Montes-Alguacil J, Alfageme-Garcia P, CerveraMarin JA, Morales-Asencio JM, et al. (2016) Establishing normative foot posture index values for the paediatric population: A cross-sectional study. Journal of Foot and Ankle Research 9(1): 24.

20. Morris C, Liabo K, Wright P, Fitzpatrick R (2007) Development of the oxford ankle foot questionnaire: Finding out how children are affected by foot and ankle problems. Child Care Health Dev 33(5): 559-568.

21. Smythe T, Wainwright A, Foster A, Lavy C (2017) What is a good result after clubfoot treatment? A Delphi-based consensus on success by regional clubfoot trainers from across Africa. PLoS One 12(12): e0190056.

22. Evans A, Chowdhury M, Rana S, Rahman S, Mahboob AH (2017) 'Fast cast' and "needle Tenotomy" protocols with the Ponseti method to improve clubfoot management in Bangladesh. Journal of Foot and Ankle Research 10(1): 49.

23. Haque M (2014) Barriers facing by parents during clubfoot treatment of children with clubfoot deformity. Mojor 26: 1(2): 1-5.

24. Nogueira MP, Farcetta M, Fox MH, Miller KK, Pereira TS, et al. (2013) Treatment of congenital clubfoot with the ponseti method. Journal of Pediatric Orthopaedics B 22(6): 583-588.

25. Zionts LE, Sangiorgio SN, Ebramzadeh E, Morcuende JA (2012) The current management of idiopathic clubfoot revisited: Results of a survey of the Posna membership. Journal of Pediatric Orthopedics 32(5): 515520.

26. Boehm S, Sinclair M (2007) Foot abduction brace in the ponseti method for idiopathic clubfoot deformity: Torsional deformities and compliance. Journal of Pediatric Orthopaedics 27(6): 712-716.

27. Zionts LE, Ebramzadeh E, Morgan RD, Sangiorgio SN (2018) Sixty years on: Ponseti method for clubfoot treatment produces high satisfaction despite inherent tendency to relapse. J Bone Joint Surg Am 100(9): 721728. 
28. Chaweerat R, Kaewpornsawan K, Wongsiridej P, Payakkaraung S, Sinnoi S, et al. (2014) The effectiveness of parent manipulation on newborns with postural clubfoot: A randomized controlled trial. J Med Assoc Thai 97(Suppl 9): S68-S72.

29. Ponseti IV, Smoley EN (2009) The classic: Congenital club foot: The results of treatment. 1963. Clinical Orthopaedics and Related Research 467(5): 1133-1145.

30. Herzenberg JE, Radler C, Bor N (2002) Ponseti versus traditional methods of casting for idiopathic clubfoot. Journal of Pediatric Orthopaedics 22(4): 517-521.
31. Ponseti IV, Zhivkov M, Davis N, Sinclair M, Dobbs MB, et al. (2006) Treatment of the complex idiopathic clubfoot. Clinical Orthopaedics and Related Research 451:171-176.

32. Roye BD, Vitale MG, Gelijns AC, Roye DP (2001) Patient-based outcomes after clubfoot surgery. Journal of Pediatric Orthopaedics 21(1): 42-49.

33. Carroll NC (2012) Clubfoot in the twentieth century: where we were and where we may be going in the twenty-first century. J Pediatr Orthop B 21(1): 1-6.

For possible submissions Click below: 